New UK row on embryo research

Edwards in fresh ethical contretemps

Yet another public controversy has erupted in Britain about the in vitro fertilization of human ova and the practices associated therewith. At the weekend and in the following days, many British newspapers reported that $\mathrm{Dr}$ Robert Edwards, of the physiology department at the University of Cambridge, had told a weekend conference that he had been carrying out experiments on viable human embryos surplus to the requirements of in vitro fertilization operations.

Dr Edwards and the surgeon Mr Patrick Steptoe were the first British exponents of this technique. Most comments this week were accompanied by condemnations of what is supposed to be going on from various public figures, including $\mathrm{Dr}$ John Havard, secretary of the British Medical Association.

So far as can be learned, none of the popular reports so far published includes an account of what Dr Edwards actually said, first in the Galton Lecture of the Eugenics Society and then by telephone to a conference improbably held at Gatwick Airport, south of London, organized by the British Medical Journalists, Association and sponsored by the Ciba Foundation.

The occasion may nevertheless be important because of the appointment by the British government last July of a committee under Dr Mary Warnock to examine the ethical problems arising from in vitro fertilization. A spokesman for the Department of Health said on Monday that the newspaper reports merely confirmed that the government had foresight in setting up the committee, which is due to report two years from now. He could not immediately say whether the committee had yet met.

On the telephone earlier this week, Dr Edwards gave an account of his paper. After the Galton Lecture, the same discourse was given by telephone to the Medical Journalists' Association. He says that he explained how, in the process of in vitro fertilization, more than a sufficient number of fertilized ova (two or three) may be produced.

What seems not to be widely appreciated about the technique is that it is conventional to maintain these embryos in culture for between two and five days, before implanting them in the uterus of the putative mother. Dr Edwards said that he had reported to the conferences that "spare" embryos had on some occasions

been observed to provide further information on the optimum time for implantation.

Dr Edwards also reported that he told the conference that he had maintained some embryos in culture for longer than five days - nine days is the maximum so far. He said that while the primary objective of this work has been to improve the efficiency of in vitro fertilization, he is also interested in more distant possibilities, and told the conferences as much.

Dr Edwards said that while conventional wisdom has it that unwanted fertilized ova should be kept in a deep-freeze, but not allowed to die, until their future could be decided, there are good reasons for making use of them in studies of fertilization, differentiation and genetic abnormality.

He said, however, that there should first be "strong ethical advice" on the subject, and that those wishing to maintain human embryos for longer than a fixed period five or nine days perhaps - should be required to have a licence to do so.

If those hurdles could be surmounted, however, Dr Edwards believes there are

\title{
Reagan no science censor
}

\section{Washington}

President Ronald Reagan denied last Friday that his Administration sought to "close off legitimate transfer of knowledge and information" when his appointees in the Pentagon caused some hundred papers to be withdrawn in the name of national security at a symposium of the Society of Photo-Optical Instrumentation Engineers in San Diego, California, last month (see Nature 23 September, p.289).

At a meeting with a group of business publishers at the White House, President Reagan told me that the Soviet Union has acquired an enormous amount of US technology because of "carelessness". $\mathrm{He}$ defended the censorship as "just an attempt to close off those avenues where, just by reason of attendance at scientific forums and seminars, they have gone home with things that they have then turned to military advantage and the sophistication of their military build-up.

"Their technological sophistication is a threat to the whole peace-loving world . . . so that is what is back of that - not any desire on our part to close off legitimate transfer of knowledge and information."

The President continued by saying that "if, here and there, something goes too far, we will rectify that" - an apparent acknowledgement that the Administration has sometimes gone too far in censorship.

There is, however, no evidence that the withdrawal of the papers at the San Diego meeting was done with presidential knowledge, even though Secretary of Defense Caspar Weinberger had been informed in substantial medical benefits ahead. While "dead against" the use of surrogate mothers to provide uterine hospitality for genetically unrelated embryos, he argues that freeze-dried congenic embryos grown at some future time to the stage at which heart or brain tissue differentiate (12-14 days) would provide adult human beings with access to compatible "spare part tissue" and thus offer an escape from immunological barriers in transplantation.

Dr Walter Hedgcock (73), a former deputy secretary of the British Medical Association, was reported by the London Standard on Monday as having been "'horrified" by Dr Edwards's disembodied speech as received at Gatwick Airport, and to be looking for a parliamentary ban on such experiments.

Dr Edwards, not for the first time in trouble with the British popular press, considers he may have been unwise to talk to an audience without being able to look its members in the eye. The incident is nevertheless potentially important because it may prompt the British government to preempt the Warnock inquiry.

advance of what his staff considered an impending "disaster" at the photooptical society meeting. In view of the attendance of Soviet scientists, $\mathrm{Mr}$ Weinberger then asked his staff to warn those due to read papers that they might be in violation of Pentagon review procedures if they did so.

"The situation is in total confusion", says Hakime Sakai, professor of physics at the University of Massachusetts at Amherst, who withdrew his paper in response to warnings from his sponsor, the Air Force's Geophysical Laboratory at Hanscomb Field. Sakai, like others, has now submitted his paper for Pentagon review, a requirement he was unaware of until days before the meeting.

While the president stressed the importance of stopping the "careless" transfer of information to the Soviet Union, he also indicated an equal interest in preserving "legitimate" transfer of information. But neither the President nor his science adviser, Dr George A. Keyworth (who, in a statement at the time, called the photooptical society incident "unfortunate and ill-timed"), said how these two goals will be met.

It is not yet clear which procedures cover the presentation of unclassified scientific material at international meetings or, for that matter, publication in the open literature. The office of Stephen D. Bryen in the Pentagon, which issued the warnings, cited a "new" regulation issued in April (numbered 5230.9) which requires central Pentagon clearance (instead of clearance 
by contractors and sponsors locally) for any papers containing "technical data" relating to equipment having military uses. Export of such equipment and related data is regulated by the 1954 International Traffic in Arms Regulations (ITAR). But the provision has previously been applied only to such things as directions for using a machine-tool device.

The Department of Commerce, which administers ITAR, sent a telegram to scientists before the meeting warning them of possible violations of ITAR, but Professor Sakai and others were unaware of this new Pentagon regulation, or that ITAR could apply to unclassified basic research, much of it based on work already published in the open literature. Sakai believed he was in compliance with another order of the Pentagon (numbered 12356), also issued in April, which said that unclassified basic research could not be classified unless it had a "direct" relationship to national security. (Professor Sakai's paper was on infrared atmospheric emissions.)

The Department of Defense now hopes to establish a steering committee to decide what to do about future scientific meetings. Professor Sakai notes that hundreds of scientific papers are presented in the United States each week that describe work funded by the Department of Defense. "It will be a monumental problem", he says, if the Reagan Administration imposes another review requirement on all those papers, as an addition to the regular peer review that the papers now receive.

Deborah Shapley

West German energy

\section{Two reactors in need of help}

\section{Bonn puts pressure on public utilities}

\section{Heidelberg}

The West German parliamentary commission of inquiry into future atomic energy policy reported last week on the comparative safety of the $300-\mathrm{MW}$ prototype fast breeder reactor under construction at Kalkar (SNR 300) and a conventional 1,300-MW high-pressure light-water reactor, Biblis B, in Hesse. Nationally, opinion about the future use of nuclear energy in West Germany and in particular about the prototype reactors is deeply divided. The commission, which included seven members of parliament and was under the chairmanship of Harald Shafer (Social Democratic Party), reflected this split by voting 11:5 that SNR 300 does not carry greater safety risks and should be put into operation. Because there is still much to be learned about the prototype, they recommend stepwise construction and careful training of personnel. The minority view was that a maximal meltdown accident with the fast breeder reactor would have far worse effects than a similar event in a conventional reactor, and the probability of its occurrence was unknown. Political, economic and security aspects should also be taken into account.

The sodium-cooled fast breeder has been 20 years in gestation. Its first project leader was Wolf Hafele, then at the Karlsruhe Atomic Energy Research Center, now a member of the commission. The construction firm is Interatom and the scheme is financed by the federal government, various utility companies and to a lesser extent the Belgians and Dutch.

The other prototype reactor in West Germany is the thorium high-temperature reactor (THTR 300) at Schmehausen in the Ruhr, which was originally planned to produce high-grade heat for the chemical industry and for coal distillation and which is being constructed by Brown-Boveri \& Co. Although the federal government is providing 75 per cent of the costs, these have risen high enough to dampen the interest of the chemical industry, especially because the reactor seems unlikely to provide the $1,000^{\circ} \mathrm{C}$ needed for coal distillation.

The construction of both reactors has been dogged by bureaucracy, litigation and political prevarication. Delays cost money and it is the escalating costs that are likely to decide the final fate of the reactors.

Andreas von Bulow, the Social Democrat minister of research and technology, has been asking industry to help make up the rising deficits. He emphasized that he could not allow two projects that have got out of hand to jeopardize basic research and the support of innovations which are more important for the German economy. The total ministry research and development budget for 1982 is DM6,500

Soviet ecology

\section{Caspian water level drops}

Soviet plans to exploit the mineral resources under the Kara-Bogaz-Gol gulf have run into trouble with conservationists working on the protection of the Caspian Sea. Beneath the Kara-Bogaz-Gol lies an underground brine lake rich in sodium sulphate - an estimated 16,000 million tonnes. Long-term development plans for the Turkmenian SSR see the brines as vital feedstocks for the rapidly expanding chemical industry of the republic.

Unfortunately, the prevailing arid conditions are rapidly reducing the water level in the Caspian. The sea has an annual intake of some $300 \mathrm{~km}^{3}$ from precipitation, but loses some $355 \mathrm{~km}^{3}$ from evaporation and $30 \mathrm{~km}^{3}$ to the needs of industry and desalination plants. The Caspian thus has a net loss of $15 \mathrm{~km}^{3}$ per year. During the past 50 years its level has sunk by $2.6 \mathrm{~m}$ and in places the shoreline has receded by several hundred metres.

Shallow areas near the shore are primarily responsible for the high level of evaporation - in particular, the KaraBogaz-Gol, from which some $5 \mathrm{~km}^{3}$ of water is lost annually. Accordingly, in 1979 it was suggested that a dyke should be constructed across the entrance to the gulf, which would then be allowed to dry out without depleting the Caspian of water.

In spite of Moscow's enthusiasm for the scheme, others are not so keen. The leading Ashkhabad newspaper, Turkmenskaya

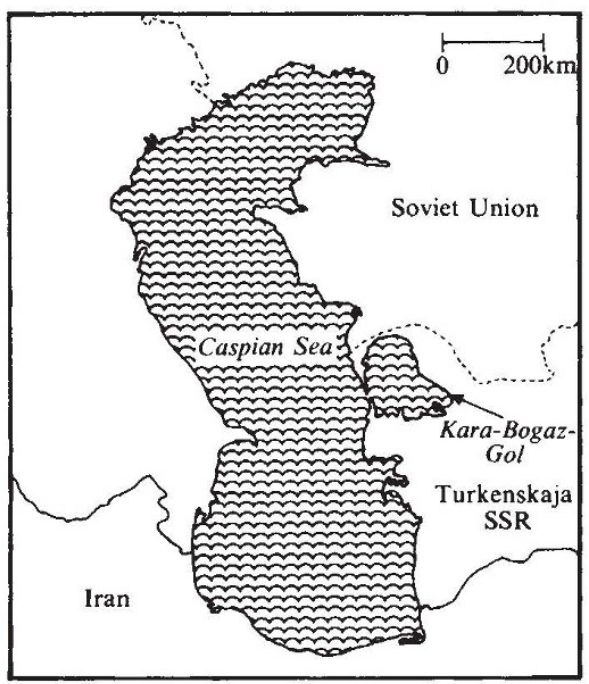

Iskra recently carried a major attack on the dam project by G. Bagirov, laboratory chief of Karabogazsulfat, the organization that exploits the brines. The dam, he said, would do immeasurable damage to the brine resources. The balance between deep and surface brines, he claims, has already been upset, so that the concentration of harmful chlorides in the deep brines is constantly rising, while that of sulphates is dropping. Moreover, if the Kara-BogazGol were allowed to dry out completely, the salts could be picked up by strong winds and ruin fertile land and fishspawning grounds for hundreds of kilometres. Meanwhile, the Caspian would gradually become more saline, as the gulf's role as a natural desalinator would be ended.

All these problems would be overcome, Bagirov claimed, if a sluice were constructed to allow limited entry of water into the gulf from the Caspian, to maintain a water balance in the gulf with at least $1 \mathrm{~km}^{2}$ of saturated natural brine. A plan for such a sluice, he claimed, has already been drawn up by the All-Union Ministry of Land Reclamation and Water Conservancy, but was shelved by the Turkmenian Ministry on the grounds that more surveys were needed. 